\title{
Construction of a Mental Health Warning Model and Proposal for Countermeasures for Community Residents in Dalian, China
}

\author{
Liang Yingnan ${ }^{1, a}$ \\ ${ }^{1}$ Department of basic teaching, Dalian Polytechnic University, Dalian, Liaoning, China \\ aliang_ying_nan@163.com
}

\begin{abstract}
New period the important task of community construction in our country is to establish a scientific and effective model of community mental health service, which has an important role in the improvement of community residents' psychological quality and in having a good life for happiness. This study, based on the analysis of the current status of supply and demand for mental health services for community-dwelling individuals in Dalian and the investigation of the mental health status of community-dwelling individuals, explores the relationship between mental health and life events and social support among community-dwelling individuals in Dalian, thus providing a theoretical basis and empirical basis for the effective maintenance of the mental health of community-dwelling individuals, and finally proposing a robust community mental health service in DalianProposal of countermeasures for the system.
\end{abstract}

Keywords: Dalian, community dwelling people, mental health warning model, community mental health service system

\section{大连市社区居民心理健康预警模型构建及对策建议研 \\ 究}

梁瑛楠 $1, a^{*}$

${ }^{1}$ 大连工业大学基础教学部, 大连, 辽宁, 中国

aliang_ying_nan@163.com

\section{摘要}

新时期我国社区建设的重要任务就是要建立科学有效的社区心理健康服务模式，这对社区居民心理素质提高 和拥有幸福美好生活有着重要作用。在分析大连市社区居民心理健康服务供需现状及调查社区居民心理健康 状况的基础上，探讨大连市社区居民的心理健康与生活事件及社会支持之间的关系，从而为有效维护社区居民 的心理健康提供理论依据和实证基础, 最终提出大连市健全社区心理健康服务体系的对策建议。

关键词: 大连, 社区居民, 心理健康预警模型, 社区心理健康服务体系

\section{1.前言}

党的十九大报告指出: “我国社会主要矛盾已经 转化为人民日益增长的美好生活需要同不平衡不充 分的发展之间的矛盾”。“加强社会心理服务体系建设, 培育自尊自信、理性平和、积极向上的社会心态”[1]。 新时代, 心理健康需求是人们对美好生活需要的重要
组成部分。社会心理服务体系建设的最基本单元就是 社区。做好社区居民心理健康服务工作既是我国加强 社会心理服务体系建设的重要一环, 也是每个老百姓 过上幸福美好生活的重要途径 ${ }^{[2]}$ 。

\section{2.研究方法与对象}

通过发放自编《大连市社区居民心理健康服务供 
需调查问卷》、症状自评量表(SCL-90)、生活事件量 表、应对方式问卷及社会支持量表调查居民的心理健 康、生活事件、应对方式及社会支持现状. 随机抽取 大连市不同区县不同发展层次等 15 社区 1200 名居民 作为调查样本进行调查, 回收 1186 份, 剔除无效问 卷 133 份, 获得有效问卷 1053 份。其中, 男性占 $45.84 \%$, 女性占 $54.16 \%$ 。

\section{3. 大连市社区居民心理健康服务供需及心理 健康现状}

\section{1. 大连市社区居民心理健康服务需求供给 现状}

$90.8 \%$ 的大连市居民认为社区需要设置心理健康 服务。在“心理健康服务对个人生活、工作、学习影响 作用”调查中，92\%的居民认为非常有帮助。

大连市社区居民对心理健康服务场所的需求选 择依次是心理咨询机构 $53.6 \%$ 、社区心理健康服务站 $27.2 \%$ 、社区保健所 $7.8 \%$ 、咨询热线 $5.5 \%$ 、社区药房 $5.2 \%$ 、综合医院专科或精神专科 $2.9 \%$ 。

大连市社区居民对心理健康服务方式的需求选 择依次是心理咨询 57\%、心理测评与评估 $18.9 \%$ 、心 理治疗服务 $17.5 \%$ 、朋友帮助 $16.1 \%$ 、读报纸杂志的 启示 $15.6 \%$ 、亲戚帮助 $11.9 \%$ 、医院就诊 $8.4 \%$ 、电话 咨询 $6.8 \%$ 。

大连市社区居民对心理健康服务人员的需求依 次是心理咨询师 $53.4 \%$ 、医生及精神卫生专家 $44.5 \%$ 、 社区专职心理工作人员 $36.1 \%$ 、自己的父母及亲人 $24.7 \%$ 、学校心理学专业教师 $18.9 \%$ 、自己解决 $9.36 \%$ 。

大连市社区居民对心理健康服务内容的需求依 次是压力与情绪管理 $61.5 \%$ 、人际关系 $52.5 \%$ 、亲子 关系问题 $51.9 \%$ 、职业择业问题 48.3\%、家庭及婚姻 $39.4 \%$ 、个人心理问题 $25.9 \%$ 、健康咨询 $24.2 \%$ 、学习 预防精神疾病发生的知识 $10.6 \%$ 。

大连市社区居民获取心理健康知识的途径依次 是网络 59\%、电视书报 48\%、广告宣传 $20.3 \%$ 、社区 卫生服务中心 $10.1 \%$ 。

另外, 对 10 个社区开展实地调研访谈, 通过与 工作人员交流, 发现目前社区能够提供的心理健康服 务还较为有限, 还无法完全社区居民所期望的心理健 康服务需求, 社区心理健康服务发展不充分的现象较 为明显。

\section{2. 大连市社区居民心理健康的总体现状}

大连市社区居民心理健康问题发生率为 $23.4 \%$ 。 具体表现在强迫发生率 $18.8 \%(198)$, 人际关系敏感发 生率 $17.7 \%(187)$, 抑郁发生率 $16.9 \%(178)$, 焦虑发生
率 $16.16 .5 \%(174)$ ，敌对发生率 $16.0 \%(169)$, 偏执发 生率 $16.0 \%(168)$, 躯体化发生率 $15.1 \%(159)$, 恐怖发 生率 $13.1 \%(138)$, 精神病性发生率 $12.9 \%(136)$ 。

大连市社区居民各因子得分均值在 $1.33 \sim 1.57$ 之间, 并未发现有明显峰值, 说明大连市社区居民各 因子得分变化程度较为接近, 心理健康保持稳定状态。

\section{4. 大连市社区居民心理健康服务供需状况的 主要问题及原因}

大连市社区居民已经意识到心理健康服务的重 要性和对自己生活、工作、学习的帮助。主要问题体 现在社区居民对心理健康服务方式需求不一; 对心理 健康服务人员要求各异; 对心理健康服务的内容需求 多样; 社区居民对心理健康服务场所因人而异; 社区 居民突出的心理问题表现在压力与情绪调适、人际关 系、亲子沟通、职业择业、家庭与婚姻关系五方面。 由此说明社区心理健康服务要根据不同人群的心理 需要, 完善服务内容与功能设置。

大连市社区心理健康服务尚不能满足社区居民 心理健康服务需求的主要原因在于目前大连市社区 心理健康服务体系还未完全建立、服务形式与科普宣 传比较单一，提供心理健康服务的社区工作人员缺乏 专业性、资源整合情况不佳、对接人员分工不明确等。

\section{5. 大连市社区居民心理健康现状的突出问题 及原因}

\section{1. 大连市社区居民心理健康现状的突出问 题}

强迫、人际关系敏感、抑郁及焦虑症状是大连市 社区居民比较突出的心理健康问题。具体表现为女性 在焦虑和精神病性等因子方面有上升趋势, 其心理健 康问题更加突出, 这与女性自身的心理特质、家庭、 社会文化等的影响有密切关系。

\section{2. 影响大连市社区居民心理健康状况的主 要原因}

\section{2 .1 生活事件对大连市社区居民心理健康的 影响}

通过研究发现，大连市社区居民经历的家庭、工 作学习及社会交往负性生活事件与居民心理健康各 因子显著正相关, 而家庭与工作学习等正向生活事件 与心理健康各因子显著负相关。这说明家庭、工作学 习及社交中的负性生活事件对人们的心理健康有显 著影响。 
表 1 大连市社区居民生活事件及人口学资料对心理健康异常的多元逐步回归预警分析

\begin{tabular}{|c|c|c|c|c|c|c|}
\hline 自变量 & $\begin{array}{c}\text { 未标准化系 } \\
\text { 数 } \\
\mathrm{B}\end{array}$ & $\begin{array}{c}\text { 未标准化系数 } \\
\mathrm{SE}\end{array}$ & 标准化系数 & $t$ & $p$ & $F$ \\
\hline $\begin{array}{c}\text { B } \\
\text { 家庭负性事 } \\
\text { 件 }\end{array}$ & 0.078 & 0.028 & 0.134 & 3.409 & 0.000 & \\
\hline $\begin{array}{c}\text { 工作负性事 } \\
\text { 件 }\end{array}$ & 0.210 & 0.022 & 0.112 & 3.093 & 0.002 & \\
\hline $\begin{array}{c}\text { 社会交往负 } \\
\text { 性事件 }\end{array}$ & 0.227 & 0.089 & 0.109 & 3.506 & 0.002 & \\
\hline \begin{tabular}{c} 
文化程度 \\
\hline 婚姻状况
\end{tabular} & 0.915 & 0.258 & 0.125 & 3.617 & 0.001 & \\
\hline
\end{tabular}

通过进一步多元逐步回归分析发现, 家庭负性生 活事件、居民文化程度、工作学习及社会交往中的负 性生活事件对大连市社区居民的心理健康影响较大。 这说明要重视因家庭生活中的负性事件引发的心理 问题，对高知分子群体、工作学习和社交中遇到的负 性生活事件要引起注意, 对于处于其他婚姻状况的人 群也需及时关注。

\subsection{2 社会支持及应对方式对大连市社区居民 心理健康的影响}

大连市社区居民采用解决问题与求助两种积极 应对方式与社会支持各因子及总分都显著正相关。而
采用自责、幻想、退避、合理化这四种消极应对方式 则与社会支持各因子及总分都显著负相关。因此，大 连市社区居民如果能采用积极的应对方式来面对生 活中遇到的负性事件, 就可以预防心理障碍的发生, 这是居民心理健康的保护因素。

通过进一步逻辑回归分析发现，大连市社区居民 在遭遇家庭、工作学习及社会交往过程中的负性生活 事件对居民心理健康异常有显著影响。采用解决问题、 自责和幻想三种应对方式对居民心理健康异常也有 显著影响。其中遇到的负性社会事件、自责和幻想均 为为危险因素, 解决问题为保护因素。

表 2 大连市社区居民应对方式与社会支持相关分析

\begin{tabular}{|c|c|c|c|c|c|c|}
\hline & $\begin{array}{c}\text { 解决 } \\
\text { 问题 }\end{array}$ & 自责 & 求助 & 幻想 & 退避 & 合理化 \\
\hline 客观支持 & $0.173^{* *}$ & $-0.193^{* *}$ & $0.141^{* *}$ & $-0.160^{* *}$ & $-0.074^{* *}$ & $-0.190^{* *}$ \\
\hline 主观支持 & $0.223^{* *}$ & $-0.140^{* *}$ & $0.133^{* *}$ & $-0.163^{* *}$ & $-0.061^{* *}$ & $-0.123^{* *}$ \\
\hline 支持利用度 & $0.186^{* *}$ & $-0.186^{* *}$ & $0.139^{* *}$ & $-0.096^{* *}$ & -0.031 & $-0.092^{* *}$ \\
\hline 社会支持总分 & $0.203^{* *}$ & $-0.158^{* *}$ & $0.184^{* *}$ & $-0.126^{* *}$ & $-0.085^{* *}$ & $-0.125^{* *}$ \\
\hline
\end{tabular}

$* * P<0.01$

\section{6. 大连市健全社区居民心理健康服务体系建 设的对策建议}

\section{1. 从思想上强化构建社区居民心理健康服 务体系、提开心理健康服务能力的必要性}

大连市社区心理健康服务工作虽然取得了一定 的成绩, 但是仍然存在一些薄弱环节, 比如社区心理 健康服务的基本设施建设不完善, 对心理健康服务的 投入还需加强, 心理健康服务“软件”与“硬件”不匹配; 社区心理健康服务管理机制不明确, 居民心理健康服
务需求与供给不平衡; 社区心理健康服务队伍和专业 人员的素质有待提高等等。社区是居民长期生活、活 动的地方, 在社区开展心理健康服务更加快捷便利, 尤其是在突发危机事件下，做好居民的心理援助与心 理辅导对于完善社区心理健康服务体系建设尤为重 要, 更容易实现预防为主、防治结合的目标 ${ }^{[3]}$ 。因此, 各级政府和社区干部要从思想意识上明确构建社区 心理健康服务体系的必要性, 加强组织领导, 注重对 社区心理健康服务的投入，把做好社区心理健康服务 工作作为完善社会治理和预警公共安全风险的重要 途径。 


\section{2.注重整体谋划与顶层设计，完善规章制度， 明确相关部门职能，稳固社区心理健康服务体 系建设}

在大连市卫健委协调领导下, 各相关职能部门立 足全局对本部门工作进行统筹规划与设计实施, 形成 各部门共同配合、信息共享、联合行动的整体化政策 措施，进一步推进大连市社区居民心理健康服务体系 构建。通过制定出台大连市社区居民心理健康服务体 系构建的基本方案，明确社区居民心理健康服务的组 织管理体系和实施细则, 明确社区心理健康服务机构 的责任及具体职责, 建立社区居民心理健康服务保障 制度, 加强社区心理健康服务的经费、人才及设施等 基础保障, 以构建必备的基础保障体系 ${ }^{[4]}$ 。

\section{3. 立足本市，建立一批专兼职相结合的高素 质社区心理健康服务人才队伍, 强化社区心理 健康服务体系建设}

依托辽宁师范大学、大连医科大学等具备心理学 专业的院校, 加大应用型心理健康教育专业人才的培 养力度。大连市各个社区可通过公开招聘心理学专业 毕业生, 保障社区心理健康服务工作者的专业性。同 时, 多元化主体参与, 充分发挥学会、协会及社会组 织的力量, 鼓励高校心理教师、医务工作者、心理学 专业学生、社工等人员, 以兼职、实习或购买社会服 务等方式加入社区心理健康服务兼职队伍中来, 充实 服务队伍 ${ }^{[5]}$ 。另外, 上级部门可定期开展专业培训, 提高社区心理健康服务工作者的专业素养, 从而使专 业的心理健康服务延伸到社区每一个角落, 并满足社 区居民益增长的心理健康服务需求, 构建大连市社区 居民心理健康服务长效机制, 提升社区居民的心理素 质 ${ }^{[6]}$ 。

\section{4. 瞄准需求, 搭建多服务平台, 保障社区心理 健康服务全方位供给}

瞄准并满足社区居民心理健康服务的基本需求 是做好社区心理健康服务体系建设的基础, 在本研究 中我们发现大连市社区居民对心理健康服务方式需 求不一、对心理健康服务人员要求各异、对心理健康 服务的内容需求多样、社区居民对心理健康服务场所 因人而异等等特点。因此, 大连市社区居民心理健康 服务要逐步完善服务内容、改善服务方式、创新服务 平台, 形成地方特色, 并能真正有效地解决好大连市 居民在情绪、压力、职业发展、家庭关系等方面存在 的心理困扰 ${ }^{[7]}$ 。

一定期开展社区居民心理健康普查行动，建立社 区居民心理健康普查档案, 形成社区居民心理健康 “大数据”系统, 及早识别社区居民可能发生的心理健 康问题。二通过对宋心理健康类科普文章、音视频、 宣传手册等方式加强社区居民心理健康科普知识宣 传。三提供多种维护心理健康的途径, 比如提供心理
服务热线、组织心理素质拓展活动、强化心理预警机 制, 科学开展预测预警、分析研判评估、强化个体危 机干预和群体危机管理, 预防和减少极端行为等等。

\section{5. 加强“非传统式” 心理健康知识传播, 打造 大连市社区居民心理健康服务智慧平台}

采用“互联网+社区心理服务”模式, 实现心理健 康服务便捷化。运用社区网站、微信公众号、手机 APP 等宣传心理健康科普知识; 定期举办线上社区心理健 康大讲堂活动, 加强各层次社区居民的心理健康意识; 对于在网站、APP 注册的社区居民, 进行个性化的心 理健康服务信息推送; 实施点单式的远程心理咨询服 务; 对社区居民心理健康数据进行统计分析, 追踪重 点人群, 并及时提供远程心理健康服务, 打造社区心 理健康智慧服务平台。

\section{7.结论}

大连市社区居民心理健康问题发生率为 $23.4 \%$, 大连市社区居民各因子得分均值在 $1.33 \sim 1.57$ 之间， 说明大连市社区居民各因子得分变化程度较为接近, 心理健康保持稳定状态。

大连市社区居民对心理健康服务方式需求不一; 对心理健康服务人员要求各异; 对心理健康服务的内 容需求多样; 社区居民对心理健康服务场所因人而异; 社区居民突出的心理问题表现在压力与情绪调适、人 际关系、亲子沟通、职业择业、家庭与婚姻关系五方 面。

大连市社区居民经历的家庭、工作学习及社会交 往负性生活事件与居民心理健康各因子显著正相关, 而家庭与工作学习等正向生活事件与心理健康各因 子显著负相关。通过回归分析发现, 家庭负性生活事 件、居民文化程度、工作学习及社会交往中的负性生 活事件对大连市社区居民的心理健康影响较大。

大连市社区居民采用解决问题与求助两种积极 应对方式与社会支持各因子及总分都显著正相关。而 采用自责、幻想、退避、合理化这四种消极应对方式 则与社会支持各因子及总分都显著负相关。通过回归 分析发现, 大连市社区居民在遭遇家庭、工作学习及 社会交往过程中的负性生活事件对居民心理健康异 常有显著影响。采用解决问题、自责和幻想三种应对 方式对居民心理健康异常也有显著影响。其中遇到的 负性社会事件、自责和幻想均为为危险因素, 解决问 题为保护因素。

从思想上强化构建社区居民心理健康服务体系、 提升心理健康服务能力的必要性; 注重整体谋划与顶 层设计, 完善规章制度, 明确相关部门职能, 稳固社 区心理健康服务体系建设; 建立一批专兼职相结合的 高素质社区心理健康服务人才队伍, 强化社区心理健 康服务体系建设; 瞄准需求, 搭建多服务平台, 保障 社区心理健康服务全方位供给; 加强“非传统式”心理 
健康知识传播，打造大连市社区居民心理健康服务智 慧平台。

\section{项目基金}

本文为辽宁省“百千万人才工程”人选科技活动 立项《辽宁省社区心理健康服务体系模式的构建研究

一以大连市为例》 $(\mathrm{C}$ 类项目) 的阶段性成果之一。

\section{REFERENCES}

[1] Yang L(2019).Supply demand status and Countermeasures for mental health services in the community. Codonopsis Forum, 1:40-43

[2] Zhang Y N(2019).Colleges under healthy China's strategy - a review of the linkage mechanism of community mental service. Shanxi youth,16:76.

[3] Xu YC,Xiang W,He YY(2018).Insights into Constructing community-dwelling mental health service systems.Academic theory,3:123-125.

[4] Gang Y,Ling H,Zhang JR,Liu JY,Lin H,Shen GH,Peng S(2019).A community oriented approach to a gridded service system of community mental health that is' met by the heart '.Psychological research,1:51-69.

[5] Song XL(2020). Supply demand status and Countermeasures for mental health services among community residents in Chengde City, China.Journal of Higher Continuing Education, 2:57-61.

[6] Fang F,Zhang KK(2019).Survey and Research on community dwelling mental health service needs.Journal of Nanjing Engineering Academy (SOCIAL SCIENCE),4:33-36.

[7] Li TT,Tian R(2019).Strengths of this community mental health service model study.liaoning economy, 11:45-47 